\title{
Evaluation of Total Adiponectin, Adipocyte Fatty Acid Binding Protein and Fibroblast Growth Factor 21 Levels in Individuals With Metabolic Syndrome
}

\author{
D. NOVOTNY ${ }^{1}$, H. VAVERKOVA ${ }^{2}$, D. KARASEK ${ }^{2}$, J. LUKES ${ }^{1}$, L. SLAVIK ${ }^{3}$, P. MALINA ${ }^{4}$, \\ J. ORSAG
}

${ }^{1}$ Department of Clinical Biochemistry, University Hospital Olomouc, Olomouc, Czech Republic, ${ }^{2}$ Third Department of Internal Medicine, Faculty of Medicine and Dentistry, Palacky University Olomouc and University Hospital Olomouc, Olomouc, Czech Republic, ${ }^{3}$ Department of HematoOncology, Faculty of Medicine and Dentistry, Palacky University Olomouc and University Hospital Olomouc, Olomouc, Czech Republic, ${ }^{4}$ Department of Clinical Biochemistry, Hospital Písek, Písek, Czech Republic

Received June 27, 2013

Accepted November 21, 2013

On-line January 8, 2014

\section{Summary}

Although many studies have investigated the relationships of several adipokines to metabolic syndrome (MetS), the interrelationships of adiponectin (ADP), adipocyte fatty acid binding protein (A-FABP) and fibroblast growth factor 21 (FGF 21) have not been described in detail. We examined 209 asymptomatic dyslipidemic patients divided into MetS+ $(n=73)$ and MetS- $(n=136)$ groups. The aim of study was to evaluate the relationships between observed adipokines, to compare the levels of total ADP, A-FABP and FGF 21 in individuals with and without MetS, and to elucidate the relationships of individual adipokines to lipid parameters, markers of insulin resistance and endothelial hemostatic markers in these groups. In MetS+ group, we found the independent positive association ADP with A-FABP (beta=0.4888, $p=0.0382$ ), A-FABP with FGF 21 (beta=0.3811, $p=0.0002$ ) and von Willebrand factor (beta $=0.4502, p=0.0013$ ), and FGF 21 with A-FABP (beta $=0.4422, p=0.0002$ ). Our study has confirmed the well-established risk profile of subjects with MetS, although clinically asymptomatic. MetS+ patients had also lower levels of ADP and higher levels of A-FABP and FGF 21. Our study evaluated the interrelationships of ADP, A-FABP and FGF 21 in asymptomatic dyslipidemic subjects with diagnosis of MetS. Especially strong association between A-FABP and FGF 21 needs to be clarified in further studies.

\section{Key words}

Metabolic syndrome • Adiponectin • Adipocyte fatty acid binding protein • Fibroblast growth factor $21 \bullet$ Dyslipidemia

\section{Corresponding author}

D. Novotný, Department of Clinical Biochemistry, University Hospital Olomouc, I. P. Pavlova 6, 77520 Olomouc, Czech Republic. E-mail: dalibor.novotny@fnol.cz

\section{Introduction}

The metabolic syndrome is a common metabolic disorder associated with increased risk of type 2 diabetes mellitus and cardiovascular diseases (Eckel et al. 2005). Although the mechanisms underlying MetS have not been well understood, recent research studies support the idea that visceral obesity plays an important role (Han et al. 2002).

Adipose tissue serves both as reservoir of the energy storage and the active endocrine tissue producing many proactive substances including adipokines. These molecules have many important metabolic effects (Funahashi et al. 1999). Inflammation of adipose tissue is characterized by infiltration of the macrophages and other types of inflammatory cells. Proinflammatory adipokines exert adverse effects on the vasculature by promoting of 
insulin resistance and monocyte infiltration into the vessel wall (Libby et al. 2011).

Adiponectin is an adipose tissue-derived adipokine with a protective role in initiation and progression of atherosclerosis through its antiinflammatory and antiatherogenic effects. Serum adiponectin levels are decreased in obesity, type 2 diabetes and patients with coronary artery disease, etc. (Haluzik et al. 2004, Shimada et al. 2004). Low adiponectin concentrations were found to independently associate with both MetS and coronary atherosclerosis (Saely et al. 2007).

Adipocyte fatty acid binding protein is an „unfavourable“ adipokine, probably a new marker and/or predictor of metabolic syndrome. A-FABP is a dominant cytoplasmic protein of mature adipocytes and a regulator of lipid and glucose metabolism, present also in macrophages of fat tissue. Oxidized LDL induces its expression. Higher levels of A-FABP were associated with increased fasting glucose, triglycerides, insulin, body mass index (BMI) and waist circumference, and decreased HDL cholesterol (HDLc) in patients with metabolic syndrome in the study of $\mathrm{Xu}$ et al. (2006). A-FABP is also considered a valuable marker of metabolic disturbances in patients with type 2 diabetes mellitus (Haluzik et al. 2009).

Fibroblast growth factor 21 is a "favourable" cytokine considered as a new metabolic regulator of noninsulin dependent glucose transport in cells. Systematic administration of FGF 21 decreases plasma levels both of glucose and triglycerides and leads to improving of lipoprotein profiles in genetic compromised FGF transgenic mice and primates (Kharitonenkov et al. 2007). Nevertheless, increased levels of FGF 21 and a negative correlation with HDL and adiponectin were found in patients with MetS (Zhang et al. 2008). In general, high levels of FGF 21 are found in cardiometabolic disorders such as obesity, MetS, type 2 diabetes, non-alcoholic fatty liver disease and coronary artery disease in human studies (Woo et al. 2013). These findings may indicate a compensatory response to metabolic stress or resistance to FGF 21. Serum FGF 21 has been implicated as a potential biomarker for early detection of these syndromes (Woo et al. 2013).

Although many studies investigated the relationships of adipokines to MetS, there is only limited information about all three parameters and their interrelationships in asymptomatic subjects with signs of MetS.
Therefore, the aim of our study was to compare the levels of ADP, A-FABP and FGF 21 in individuals with and without MetS, and to elucidate the relationships of individual adipokines to lipid parameters, markers of insulin resistance and endothelial hemostatic markers in these groups.

\section{Materials and Methods}

\section{Study design and subjects}

The study was performed with asymptomatic dyslipidemic subjects (i.e. individuals without history of clinically manifest atherosclerosis- coronary artery disease, heart failure, cerebrovascular ischemic disease and peripheral vascular disease, with altered plasma lipids), their relatives and spouses, without lipidmodifying therapy. They had been examinated for the first time in the Lipid Centre of the 3rd Department of Internal Medicine, University Hospital Olomouc, Czech Republic, during the period from January 2009 to March 2012. All subjects were tested for the signs of secondary hyperlipidemia: diabetes mellitus, hypothyroidism, renal or hepatic diseases and nephrotic syndrome. Other exclusion criteria were as follows: history of clinically manifested atherosclerosis presented by coronary artery disease, cerebrovascular disease and peripheral arterial disease, hypolipidemic therapy in previous 8 weeks, hormone therapy and clinical presence of acute infections. All individuals filled out a questionnaire on their previous medical history, especially cardiovascular status, medication and smoking habits. Body mass index and systolic and diastolic blood pressure (SBP, DBP) were also determinated. The study was reviewed and approved by Ethics Committee of Medical Faculty and University Hospital Olomouc and informed consent was obtained from all participants.

Individuals who met criteria mentioned above $(n=209)$ were divided into two groups: patients with presence of metabolic syndrome (MetS+, n=73, 31 males, 42 females), and individuals with absence of metabolic syndrome (MetS-, n=136, 74 males, 62 females). Following criteria were used for identification of MetS according to NCEP- ATPIII Panel 2001: waist circumference $($ men $>102 \mathrm{~cm}$, women $>88 \mathrm{~cm}$ ), triglycerides $(\mathrm{TG}) \geq 1.7 \mathrm{mmol} / \mathrm{l}$, HDL cholesterol (men $<1.04 \mathrm{mmol} / \mathrm{l}$, women $<1.30 \mathrm{mmol} / \mathrm{l}$ ), blood pressure $\geq 130 / \geq 85 \mathrm{~mm} \mathrm{Hg}$ and fasting glucose $\geq 6.1 \mathrm{mmol} / \mathrm{l}$. The presence of minimally three of following factors was sufficient for diagnosis of MetS. 


\section{Laboratory analysis}

Venous blood samples were drawn in the morning after a 12-h fast. After centrifugation, the serum was used for other analyses. For assessment of thrombotic markers, venous blood was collected in 3.8\% sodium citrate tubes and plasma was obtained after centrifugation.

Routine serum biochemical parameters were analyzed on Modular SWA (Roche, Basel, Switzerland) in the day of blood collection. Concentrations of adipokines and other special analytes were measured in the sample aliquotes stored at $-80(-20)^{\circ} \mathrm{C}$, no longer than 6 months - see below in text.

Total cholesterol (TC), TG and HDLc were determined enzymatically on a Modular SWA system (Roche, Basel, Switzerland). Determination of HDLc was realized by a direct method without precipitation of apoB containing lipoproteins. Low density lipoprotein cholesterol (LDLc) levels were calculated using Friedewald formula (for TG less than $4.5 \mathrm{mmol} / \mathrm{l}$ ). Another calculated parameters were as follows: non-HDL-cholesterol (nonHDLc $=$ TC-HDLc) and atherogenic index of plasma (AI) (logTG/HDLc). Concentration of Apo B and Apo A1 were determined immunoturbidimetrically using Tina-Quant $\mathrm{ApoB}$ and ApoA-1 kits (Roche, Basel, Switzerland). Lipoprotein(a) [Lp(a)] was determined immunoturbidimetrically using Tina-Quant Lipoprotein(a) TQ kit (Roche, Basel, Switzerland). C-reactive protein (CRP) was assessed by an ultrasensitive immunoturbidimetric method using the kit Tina-Quant (Roche, Basel, Switzerland). Glucose was determined using GOD-PAP method (Roche, Basel, Switzerland). N-terminal prohormone of brain natriuretic peptide (NT-proBNP) was determined by ECLIA method (Elecsys pro BNP reagent kit, Roche, Basel, Switzerland). All tests were measured from fresh sera in the day of blood collection.

Insulin was determined by the commercially available kit (Immunotech, Marseille, France) using specific antibodies by the IRMA method. C-peptide and proinsulin (PINS) were determined using the commercially available kits: C-peptide (Immunotech, Marseille, France), and Proinsulin (DRG Instruments GmbH, Marburg, Germany), by the IRMA method, and RIA method, respectively. The sample aliquotes were stored at $-20^{\circ} \mathrm{C}$, no longer than 6 months.

The following thrombotic markers were examined from human plasma stored at $-20^{\circ} \mathrm{C}$ : von Willebrand factor (immunoturbidimetric assay,
Instrumentation Laboratory Spa, Milan, Italy), plasminogen activator inhibitor-1 (PAI-1) and tissue plasminogen activator (tPA) (ELISA, Technoclone, Vienna, Austria).

Total adiponectin, A-FABP and FGF 21 were measured in serum (one separate aliquot stored at $-80{ }^{\circ} \mathrm{C}$ until the day of analysis) by following imunochemical kits: Human Adiponectin ELISA, Human A-FABP ELISA and Human FGF 21 ELISA (all Biovendor Laboratory Medicine Inc., Brno, Czech Republic), according to the manufacturer's instructions and after verification of all three methods. Both the intra- and inter-assay coefficients of variation were below $10 \%$ for all parameters.

Serum levels of the soluble adhesion molecules s-ICAM-1 and sVCAM-1 were determined by immunoenzymatic assay using commercially available kits s-ICAM-1 and sVCAM-1 (both Immunotech, Marseille, France) from one separate aliquot stored at $-20{ }^{\circ} \mathrm{C}$.

\section{Statictical analysis}

All values are expressed as means \pm standard deviation (SD) and parameters with skewed distribution also as medians. The Kolmogorov-Smirnov test was used to test for normal distribution. Variables with skewed distribution (CRP, TG, Lp(a), fibrinogen, vWF, tPA, PAI-1, insulin, C-peptide, PINS, ADP, FGF 21, AFABP, NT-proBNP) were log transformed in order to normalize their distribution before statistical analysis. Differences in variables between individual groups were analyzed with ANCOVA after adjustment for age and sex. For statistical evaluation of a correlation between individual parameters we used a Pearson correlation analysis for analytes with normal distribution, and a univariate Spearman correlation analysis for variables with skewed distribution. Multiple regression analysis was performed for testing of an independent association between dependent and independent variables. Statistical analysis was performed using SPSS for Windows version 12.0 (Chicago, IL, USA). Probability values of $\mathrm{p}<0.05$ were considered as statistically significant.

\section{Results}

The basic clinical and laboratory characteristics of all subjects and divided into two groups according to absence/presence of MetS are summarized in Table 1. Besides of expected unfavourable lipid and lipoprotein 
Table 1. Basic characteristics of all individuals and subjects without MetS and with MetS.

\begin{tabular}{|c|c|c|c|}
\hline & $\begin{array}{l}\text { All individuals } \\
\qquad \mathbf{n}=\mathbf{2 0 9}\end{array}$ & $\begin{array}{l}\text { MetS- } \\
\mathrm{n}=\mathbf{1 3 6}\end{array}$ & $\begin{array}{c}\text { Met } \mathbf{S}+ \\
\mathbf{n}=73\end{array}$ \\
\hline Age (years) & $46.7 \pm 14.5$ & $44.7 \pm 15.9$ & $50.1 \pm 11.0$ \\
\hline$C R P(m g / l)$ & $3.8 \pm 10.1(1.6)$ & $2.9 \pm 4.2(1.4)$ & $3.8 \pm 4.5(2.3) *$ \\
\hline TC (mmol/l) & $6.69 \pm 1.84$ & $6.42 \pm 1.48$ & $7.12 \pm 2.25 * *$ \\
\hline$T G(\mathrm{mmol} / \mathrm{l})$ & $3.01 \pm 4.21(1.77)$ & $1.76 \pm 1.74(1.38)$ & $4.34 \pm 6.18(3.31) * * *$ \\
\hline$A I$ & $0.1931 \pm 0.4373$ & $-0.0223 \pm 0.3207$ & $0.5827 \pm 0.3563 * * *$ \\
\hline nonHDL (mmol/l) & $5.33 \pm 1.92$ & $4.87 \pm 1.51$ & $6.10 \pm 2.27 * * *$ \\
\hline$H D L c(\mathrm{mmol} / \mathrm{l})$ & $1.37 \pm 0.46$ & $1.55 \pm 0.45$ & $1.03 \pm 0.23 * * *$ \\
\hline$L D L c(\mathrm{mmol} / \mathrm{l})$ & $4.06 \pm 1.57$ & $4.06 \pm 1.33$ & $3.97 \pm 1.91$ \\
\hline Apo A1 $(g / l)$ & $1.54 \pm 0.37$ & $1.65 \pm 0.38$ & $1.34 \pm 0.25 * * *$ \\
\hline Apo B $(g / l)$ & $1.21 \pm 0.38$ & $1.13 \pm 0.34$ & $1.33 \pm 0.43 * * *$ \\
\hline $\operatorname{Lp}(a)(g / l)$ & $0.399 \pm 0.465(0.201)$ & $0.409 \pm 0.455(0.221)$ & $0.381 \pm 0.489(0.189)$ \\
\hline Fibrinogen $(g / l)$ & $2.98 \pm 0.76(2.80)$ & $2.90 \pm 0.70(2.73)$ & $3.04 \pm 0.64(2.91)$ \\
\hline$v W F(\%)$ & $130 \pm 55(118)$ & $128 \pm 50(118)$ & $132 \pm 60(118)$ \\
\hline$t P A(n g / m l)$ & $3.35 \pm 2.43(3.0)$ & $2.79 \pm 0.88(2.8)$ & $4.11 \pm 2.82(3.0) * * *$ \\
\hline PAI-1 (ng/ml) & $65 \pm 42(58)$ & $56 \pm 36(44)$ & $83 \pm 48(78) * *$ \\
\hline sICAM-1 $(\mathrm{ng} / \mathrm{ml})$ & $358 \pm 148$ & $335 \pm 128$ & $389 \pm 173 *$ \\
\hline sVCAM-1 $(\mathrm{ng} / \mathrm{ml})$ & $743 \pm 360$ & $709 \pm 327$ & $819 \pm 411 *$ \\
\hline Glucose (mmol/l) & $5.38 \pm 1.04$ & $5.10 \pm 0.56$ & $5.92 \pm 1.46 * * *$ \\
\hline Insulin (mIU/l) & $10.3 \pm 6.6(8.5)$ & $8.4 \pm 4.5(7.5)$ & $13.7 \pm 8.2(11.7) * * *$ \\
\hline C-peptide $(m g / l)$ & $2.7 \pm 1.4(2.5)$ & $2.3 \pm 1.0(2.2)$ & $3.6 \pm 1.7(3.4) * * *$ \\
\hline$B M I\left(\mathrm{~kg} / \mathrm{m}^{2}\right)$ & $26.99 \pm 4.75$ & $25.19 \pm 4.17$ & $30.36 \pm 4.05 * * *$ \\
\hline Waist $(\mathrm{cm})$ & $91.1 \pm 14.2$ & $85.9 \pm 11.9$ & $101.0 \pm 12.7 * * *$ \\
\hline PINS (mIU/l) & $14.8 \pm 10.5(11.4)$ & $12.0 \pm 8.3(9.6)$ & $20.3 \pm 12.2(16.6) * * *$ \\
\hline$A D P(m g / l)$ & $8.6 \pm 5.2(7.4)$ & $9.4 \pm 5.0(8.0)$ & $7.0 \pm 5.3(5.4) * * *$ \\
\hline$F G F 21(n g / l)$ & $317.7 \pm 440.4(197.6)$ & $222.3 \pm 299.9(156.5)$ & $471.4 \pm 531.7(305.6) * * *$ \\
\hline$A-F A B P(\mu g / l)$ & $26.2 \pm 17.9(21.9)$ & $22.2 \pm 12.7(19.9)$ & $33.8 \pm 23.5(29.1) * * *$ \\
\hline$N T-p r o B N P(n g / l)$ & $65.7 \pm 82.1(40.7)$ & $65.4 \pm 84.2(44.5)$ & $67.7 \pm 81.0(41.4)$ \\
\hline$S B P(m m ~ H g)$ & $128.7 \pm 15.2$ & $125.1 \pm 13.6$ & $136.1 \pm 15.6 * * *$ \\
\hline$D B P(m m ~ H g)$ & $77.8 \pm 8.7$ & $75.9 \pm 8.3$ & $81.7 \pm 8.0 * * *$ \\
\hline
\end{tabular}

Data are expressed as means \pm standard deviations, in parameters with skewed distribution also as medians (in parentheses). Differences in variables between groups were analyzed with ANCOVA after adjustment for age and sex. Variables with skewed distribution (CRP, TG, Lp(a), fibrinogen, vWF, tPA, PAI-1, insulin, C-peptide, PINS, ADP, FGF 21, A-FABP, NT-proBNP) were log transformed to normalize their distribution before statistical analyses. Significant differences between MetS- and MetS+ groups: $* \mathrm{p}<0.05, * * \mathrm{p}<0.01, * * * \mathrm{p}<0.001$. CRP, C-reactive protein; TC, total cholesterol; TG, triglycerides; HDLc, high density lipoprotein cholesterol; LDLc, low density lipoprotein cholesterol; nonHDL=TC-HDLC; AI, atherogenic index of plasma (logTG/HDLc); Apo, apolipoprotein; $\mathrm{LP}(\mathrm{a})$, lipoprotein (a); vWF, von Willebrand factor; tPA, tissue plasminogen activator; PAI-1, plasminogen activator inhibitor-1; sICAM-1, soluble intercellular adhesion molecule-1; sVCAM-1, soluble vascular cell adhesion molecule-1; BMI, body mass index; PINS, proinsulin; ADP, adiponectin; FGF 21, fibroblast growth factor 21; A-FABP, adipocyte fatty acid binding protein; NT-proBNP, N-terminal prohormone of brain natriuretic peptide; SBP, systolic blood pressure; DBP, diastolic blood pressure.

profiles (elevated TC, TG, nonHDLc, AI, Apo B, and decreased levels of HDLc and Apo A1) and pronounced insulin resistance (increased levels of glucose, insulin, proinsulin and C-peptide), individuals with MetS had significantly elevated concentrations of endothelial and hemostatic markers tPA, PAI-1 and adhesive molecules
sVCAM-1 and sICAM-1. Adiponectin was significantly lower in MetS+ $(\mathrm{p}<0.001)$, whilst A-FABP and FGF 21 concentrations were elevated in comparison with MetSgroup $(\mathrm{p}<0.001)$.

In Table 2, significant correlations of adipokines with other parameters in MetS+ and MetS- groups are 
introduced. In MetS+ group, ADP positively correlated with age, HDLc, Apo A1, A-FABP and NT-proBNP, and negatively with sex and waist circumference. A-FABP positively correlated with vWF, ADP, FGF 21 and NT-proBNP, whereas FGF 21 positively correlated with TG, AI, vWF, PAI-1, A-FABP and waist circumference.

Table 2. Significant correlations of adipokines with other parameters in MetS+ and MetS- groups ( $r$ and $p$ values).

a) ADP

\begin{tabular}{lccccccccc} 
& Age & Sex & Waist & HDLc & Apo A1 & vWF & A-FABP & NT-proBNP \\
\hline \multirow{2}{*}{ ADP Met $S+$} & $\mathbf{0 . 3 8 6}$ & $\mathbf{- 0 . 5 2 0}$ & $\mathbf{- 0 . 4 1 4}$ & $\mathbf{0 . 4 9 9}$ & $\mathbf{0 . 3 5 5}$ & 0.139 & $\mathbf{0 . 2 6 7}$ & $\mathbf{0 . 4 1 1}$ \\
& $\mathbf{0 . 0 0 1}$ & $\mathbf{0 . 0 0 0}$ & $\mathbf{0 . 0 0 1}$ & $\mathbf{0 . 0 0 0}$ & $\mathbf{0 . 0 0 2}$ & 0.254 & $\mathbf{0 . 0 2 2}$ & $\mathbf{0 . 0 0 0}$ \\
ADP Met $S-$ & $\mathbf{0 . 2 6 1}$ & $\mathbf{- 0 . 3 9 9}$ & $\mathbf{- 0 . 2 5 3}$ & $\mathbf{0 . 4 7 6}$ & $\mathbf{0 . 5 0 7}$ & $\mathbf{0 . 3 1 0}$ & 0.124 & $\mathbf{0 . 4 4 2}$ \\
& $\mathbf{0 . 0 0 2}$ & $\mathbf{0 . 0 0 0}$ & $\mathbf{0 . 0 0 8}$ & $\mathbf{0 . 0 0 0}$ & $\mathbf{0 . 0 0 0}$ & $\mathbf{0 . 0 0 0}$ & 0.151 & $\mathbf{0 . 0 0 0}$ \\
\hline
\end{tabular}

\section{b) A-FABP}

\begin{tabular}{llllllll}
\hline & Age & BMI & Waist & vWF & ADP & FGF 21 & NT-proBNP \\
\hline \multirow{2}{*}{-FABP Met +} & 0.117 & 0.050 & 0.046 & $\mathbf{0 . 4 0 4}$ & $\mathbf{0 . 2 6 7}$ & $\mathbf{0 . 5 2 1}$ & $\mathbf{0 . 3 9 9}$ \\
& 0.326 & 0.678 & 0.729 & $\mathbf{0 . 0 0 1}$ & $\mathbf{0 . 0 2 2}$ & $\mathbf{0 . 0 0 0}$ & $\mathbf{0 . 0 0 1}$ \\
A-FABP MetS- & $\mathbf{0 . 3 2 7}$ & $\mathbf{0 . 3 7 9}$ & $\mathbf{0 . 2 8 8}$ & $\mathbf{0 . 2 6 6}$ & 0.124 & $\mathbf{0 . 2 8 2}$ & $\mathbf{0 . 1 9 8}$ \\
& $\mathbf{0 . 0 0 1}$ & $\mathbf{0 . 0 0 0}$ & $\mathbf{0 . 0 0 2}$ & $\mathbf{0 . 0 0 2}$ & 0.151 & $\mathbf{0 . 0 0 1}$ & $\mathbf{0 . 0 2 3}$
\end{tabular}

c) FGF 21

\begin{tabular}{lcccccc}
\hline & TG & AI & vWF & PAI-1 & A-FABP & Waist \\
\hline \multirow{2}{*}{ FGF 21 MetS+ } & $\mathbf{0 . 3 7 4}$ & $\mathbf{0 . 3 4 0}$ & $\mathbf{0 . 3 6 2}$ & $\mathbf{0 . 2 2 3}$ & $\mathbf{0 . 5 2 1}$ & $\mathbf{0 . 2 5 6}$ \\
& $\mathbf{0 . 0 0 1}$ & $\mathbf{0 . 0 0 1}$ & $\mathbf{0 . 0 0 2}$ & $\mathbf{0 . 0 5 0}$ & $\mathbf{0 . 0 0 0}$ & $\mathbf{0 . 0 5 0}$ \\
FGF 21 MetS- & $\mathbf{0 . 2 4 0}$ & $\mathbf{0 . 1 7 2}$ & 0.079 & $\mathbf{0 . 2 0 1}$ & $\mathbf{0 . 2 8 2}$ & 0.050 \\
& $\mathbf{0 . 0 0 5}$ & $\mathbf{0 . 0 4 6}$ & 0.371 & $\mathbf{0 . 0 2 2}$ & $\mathbf{0 . 0 0 1}$ & 0.606 \\
\hline
\end{tabular}

Pearson correlation analysis for parameters with normal distribution. Spearman correlation analysis for parameters with skewed distribution (TG, vWF, tPA, PAI-1, ADP, FGF 21, A-FABP, NT-proBNP). Bold values indicate significance at $p<0.05$.

In order to evaluate the independent association of followed up parameters with ADP, A-FABP and FGF 21, the multiple regression analysis with adipokines as dependent variables and correlated parameters as independent predictors was performed (see Table 3). In MetS+ group, ADP was independently positively associated with A-FABP (beta=0.4888, $\mathrm{p}<0.05$ ), A-FABP was positively associated with FGF 21 (beta $=0.3811$, $\mathrm{p}<0.001)$ and vWF (beta $=0.4502, \mathrm{p}<0.01)$, whilst FGF 21 was positively associated only with A-FABP (beta $=0.4422, \mathrm{p}<0.001$ ). In MetS- group, ADP was positively associated with vWF and negatively with sex, A-FABP was positively associated with FGF 21, vWF and BMI, and FGF 21 was positively associated with A-FABP, TG, and negatively with AI.

\section{Discussion}

Our study confirms the well-established risk profile of subjects with MetS, although clinically asymptomatic. They had unfavourable lipid and lipoprotein profiles, increased parameters of insulin resistance, and significantly elevated concentrations of endothelial hemostatic markers represented by tPA, PAI-1 and adhesive molecules, in comparison with MetSindividuals. Decreased levels of ADP in MetS+ individuals are not surprising and they are consistent with recent literature (Ryo et al. 2004, Saely et al. 2007), as well as the increase of A-FABP levels (Horakova et al. 2011, Park et al. 2012), and FGF 21 concentrations (Zhang et al. 2008, Chen et al. 2011, Reinehr et al. 2012). 
Table 3. Independent associations of ADP, A-FABP and FGF 21 as result of the multiple regression analysis (bold values).

a) ADP

\begin{tabular}{lccc} 
& A-FABP & vWF & sex \\
\hline ADP MetS + & beta $=\mathbf{0 . 4 8 8 8}$ & NS & NS \\
ADP MetS - & $\boldsymbol{p}=\mathbf{0 . 0 3 8 2}$ & $\mathrm{NS}$ & beta $=\mathbf{0 . 4 3 3 2}$ \\
$\boldsymbol{p}=\mathbf{0 . 0 2 4 5}$ & $\mathbf{b e t a}=\mathbf{- 0 . 0 6 0 9}$ \\
& & $\boldsymbol{p}=\mathbf{0 . 0 4 4 7}$ \\
\hline
\end{tabular}

b) A-FABP

\begin{tabular}{lccc}
\hline FGF 21 & vWF & BMI \\
\hline A-FABP MetS + & beta $=\mathbf{0 . 3 8 1 1}$ & beta $=\mathbf{0 . 4 5 0 2}$ & NS \\
A-FABP Met $S-$ & $\boldsymbol{p}=\mathbf{0 . 0 0 0 2}$ & $\boldsymbol{p}=\mathbf{0 . 0 0 1 3}$ & beta $=\mathbf{0 . 3 7 8 5}$ \\
& beta $=\mathbf{0 . 1 4 9 1}$ & beta $=\mathbf{0 . 3 5 2 4}$ & $\boldsymbol{p}=\mathbf{0 . 0 0 2 6}$ \\
\hline
\end{tabular}

c) FGF 21

\begin{tabular}{cccc} 
& A-FABP & TG & AI \\
\hline FGF 21 MetS + & beta $=\mathbf{0 . 4 4 2 2}$ & NS & NS \\
FGF 21 MetS- & beta $=\mathbf{0 . 0 0 0 2}$ & & beta $=\mathbf{- 0 . 1 1 0 5}$ \\
& $\boldsymbol{p}=\mathbf{0 . 0 0 2 6}$ & beta $=\mathbf{0 . 1 1 5 0}$ & $\boldsymbol{p}=\mathbf{0 . 0 3 5 8}$ \\
\hline
\end{tabular}

Bold values indicate significance at $p<0.05$. NS - no significance.

Significant correlations of adipokines with other selected parameters in MetS+ and MetS- groups as a result of univariate correlation analysis are described in Table 2. There are minimally three interesting points in this summary: 1. positive correlation of ADP and A-FABP with NT-proBNP in both groups, which was amplified especially in MetS+ group (although no differences were seen in NT-proBNP levels), 2. only weak or no correlation of A-FABP with metabolic and anthropometric parameters of insulin resistance, and 3. strong correlation of A-FABP and FGF 21 in both observed groups.

Adiponectin is one of the few adipokines that has multiple favourable effects on the prevention of cardiovascular disease through its pleiotropic actions on the blood vessels and the heart. In our study, we have verified correlations with many clinical, anthropometrical and laboratory parameters (age, sex, waist circumference, HDLc, Apo A1), mostly well described in previous studies. But positive relationship of ADP to A-FABP as an independent predictor was seen only in MetS+ individuals and was confirmed by multiple regression analysis (however, A-FABP as dependent variable did not correlate with ADP in this group). We can speculate about the reason of this relationship. One of the main beneficial functions of adiponectin is cardioprotective action ( $\mathrm{Xu}$ et al. 2012). The antiapoptotic activity represents a key mechanism, whereby ADP protects against cardiac injury (Tao et al. 2007). In cardiomyocytes, adiponectin promotes decrease of oxidative/nitrosative stress, apoptosis, fibrosis and inflammation and increase of fatty acid and glucose uptake. On the other side, despite its atheroprotective properties, ADP has been associated with both decreased (Pischon et al. 2004, Frystyk et al. 2007) and increased (Lindsay et al. 2005) risk of cardiovascular disease and/or mortality. In our recent study, the positive association of ADP was found with thrombomodulin, vWF and sVCAM-1 in dyslipidemic subjects, which might contribute to increased risk of cardiovascular disease associated with higher plasma ADP levels (Vaverkova et al. 2013).

Data from animal studies support an etiological role of A-FABP in cardiovascular disease (Furuhashi et 
al. 2008). A-FABP has been identified as a major cardiodepressant factor that confers the suppressive effect of adipocytes on cardiac contractile functions (Lamounier-Zepter et al. 2009). Thus, independent association of ADP with A-FABP in MetS+ group may be connected with the relationship of these adipokines to cardiac and/or vascular functions, and may reflect compensatory response of ADP to higher risk of cardiovascular disease. In addition, both parameters have correlated positively with NT-proBNP (see Table 2), which has been shown to be an accurate and sensitive diagnostic marker in patients with heart failure, although, after multiple regression analysis, the association has lost significance in our study. Von Eynatten et al. (2006) have investigated the relationship of adiponectin to markers of inflammation, atherogenic dyslipidemia and heart disease in patients with coronary artery disease. After adjusting for age and sex, adiponectin was associated positively with HDL cholesterol and NT-proBNP. Moreover, several studies found the relationship between A-FABP and coronary atherosclerosis (Miyoshi et al. 2010, Rhee et al. 2009) and its possible role in the development of cardiac dysfunction have been suggested, including positive correlation with NT-proBNP (Zhou et al. 2011).

In recent cross-sectional studies, serum A-FABP correlated with parameters of IR (glucose, insulin, waist circumference, BMI) in obese individuals, patients with type 2 diabetes mellitus, patients with familial combined hyperlipidemia and patients with metabolic syndrome (Kralisch et al. 2013). But we have found only weak or no correlation of A-FABP with these parameters in MetS+ group, although significant differences were observed between MetS+ and MetS- groups, as shown in Table 1. We speculate about relatively small number of individuals in MetS + group. In any case, this phenomenon is surprising and we have no other relevant explanation for it.

A-FABP is a key proinflammatory mediator that links obesity with cardiovascular disease in humans $\mathrm{Xu}$ et al. 2012). The proatherogenic activity is mediated by its direct action on macrophages, independently of lipid metabolism and insulin sensitivity (Hoo et al. 2008). In MetS + group, the positive correlation between A-FABP with vWF, ADP, FGF21 and NT-proBNP was observed, but independent relationship with only vWF and FGF 21 was revealed by the multiple regression analysis (see Table 3). Positive association with vWF is in accordance with our previous study (Karasek et al. 2012) and supports the role of A-FABP in development of endothelial dysfunction. The independent association with FGF 21 is discussed below.

Fibroblast growth factor 21 is a member of the FGF superfamily, with relevant metabolic actions (Iglesias et al. 2012). FGF 21 has been recently considered as a metabolic hormone regulated by nutritional status, with multiple beneficial effects on glucose homeostasis and lipid metabolism in animal models. Indeed, FGF 21 improves insulin sensitivity, glucose, and lipid homeostasis and preserves beta-cell functions in diabetic animal models (Kharitonenkov et al. 2007, Coskun et al. 2008, Kralisch et al. 2011). However, increased levels of FGF 21 and negative correlation with HDLc and adiponectin were found in patients with MetS (Zhang et al. 2008). In general, high levels of FGF 21 are found in cardiometabolic disorders such as obesity, MetS, type 2 diabetes, non-alcoholic fatty liver disease and coronary artery disease in human studies (Woo et al. 2013).

As shown in Table 2, FGF 21 has positively correlated with waist, TG, AI, vWF, PAI-1 and A-FABP in MetS+ group. Some of these relationships have been described in previous studies: higher levels of FGF 21 and positive correlation with $\mathrm{TG}$ in patients with coronary artery disease and dyslipidemia (Lin et al. 2010), independent association with TG and LDLc in patients with impaired glucose tolerance and/or type 2 diabetes (Chen et al. 2011) or above-mentioned study of Zhang et al. (2008) revealing positive correlation with adiposity and TG in obese individuals with metabolic syndrome.

There are only limited information about the relationships of FGF 21 and endothelial hemostatic markers in recent literature. PAI-1 is probably less specific marker of endothelial damage (Karasek et al. 2012). It originates from several sites, including endothelium, liver and adipose tissue, and higher levels may not reflect endothelial dysfunction. In our recent study, positive associations of ADP and vWF were found in dyslipidemic patients (Vaverkova et al. 2013). Correlation of FGF 21 with vWF is surprising and may reflect higher risk of atherothrombosis in MetS+ group in general. However, both relationships have lost significance after the multiple regression analysis.

The favourable effects in animal studies would support the potential role of FGF 21 as a therapeutic agent for diabetes and obesity (Dostalova et al. 2009, Woo et al. 2013). However, high serum FGF 21 levels were observed in obese individuals, and patients with 
obesity-related disorders and insulin resistance (Zhang et al. 2008, Chen et al. 2011). The causes of this phenomenon need to be clarified. FGF 21 resistance has been proposed as one of the causes in animal study (Fisher et al. 2010).

The most important finding of our study was the strong reciprocal positive association of FGF 21 with A-FABP levels in both investigated groups, with pronounced relationship in MetS + group $(p=0.0002)$. One of the reasons of elevated FGF 21 could be the presence of compensatory response to higher metabolic stress presented by high levels of A-FABP. As mentioned above, high levels of FGF 21 were found in cardiometabolic disorders such as obesity, MetS, type 2 diabetes, non-alcoholic fatty liver disease and coronary artery disease in human studies (Woo et al. 2013). It seems likely that this circulating FGF 21 is derived from the liver, perhaps due to the induction of FGF 21 by elevated hepatic lipid and carbohydrate levels (Huating et al. 2013). But it is not clear if circulating A-FABP is only a strong marker of metabolic disturbances or one of its primary causes (Haluzik et al. 2009).

FGF 21 resistance has been proposed as one of the causes for the raised circulating levels in obese mice (Fischer et al. 2010). For activation of FGF receptor mediated signaling, FGF 21 has to bind a FGF receptor: beta-Klotho complex (Kharitonenkov et al. 2008). BetaKlotho is highly expressed in metabolically active tissues including adipose tissue, liver and pancreas. A recent study suggests that adipose tissue inflammation in obesity can lead to the repression of beta-Klotho expression by TNF alpha and impaired FGF 21 in adipocytes (DiazDelfin et al. 2012). Similar actions may also lead to
FGF 21 resistance in subclinical inflammation such as metabolic syndrome, type 2 diabetes and coronary artery disease (Woo et al. 2013). Therefore, it is possible that A-FABP (as a key proinflammatory mediator that links obesity with cardiovascular disease) may participate in the process of FGF 21 resistance, for example by its proinflammatory effect. Further studies are needed to address the mechanisms underlying the observed relationship.

\section{Conclusion}

Although many studies investigated the relationships of several adipokines to metabolic syndrome, we have first evaluated the interrelationships of ADP, A-FABP and FGF 21 in dyslipidemic subjects with signs of MetS. We have found independent positive association of ADP with A-FABP, and, to the best of our knowledge, we have first documented strong positive reciprocal association between FGF 21 and A-FABP in dyslipidemic subjects highlighted in MetS+ group. In addition, we have confirmed previously described independent relationship of A-FABP and vWF.

\section{Conflict of Interest}

There is no conflict of interest.

\section{Acknowledgements}

Supported by the Institutional Support of Ministry of Health, Czech Republic, Nr.1 RVO-FNOL2013. Supported by the Internal Grant Agency of Palacky University, Czech Republic, Nr. LF_2013_010.

\section{References}

CHEN C, CHEUNG BM, TSO AW, WANG Y, LAW LS, ONG KL, WAT NM, XU A, LAM KS: High plasma level of fibroblast growth factor 21 is an independent predictor of type 2 diabetes: a 5.4-year population based prospective study in Chinese subjects. Diabetes Care 34: 2113-2115, 2011.

COSKUN T, BINA HA, SCHNEIDER MA, DUNBAR JD, HU CC, CHEN Y, MOLLER DE, KHARITONENKOV A: Fibroblast growth factor 21 corrects obesity in mice. Endocrinology 149: 6018-6027, 2008.

DIAZ-DELFIN J, HONDARES E, IGLESIAS R, GIRALT M, CAELLES C, VILLARROYA F: TNF-alpha represses beta-Klotho expression and impairs FGF21 action in adipose cells; involvement of JNK1 in the FGF21 pathway. Endocrinology 153: 4238-4245, 2012.

DOSTALOVA I, HALUZIKOVA D, HALUZIK M: Fibroblast Growth Factor 21: A novel metabolic regulator with potential therapeutic properties in obesity/type 2 diabetes mellitus. Physiol Res 58: 1-7, 2009.

ECKEL RH, GRUNDY SM, ZIMMENT PZ: The metabolic syndrome. Lancet 365: 1415-1428, 2005.

FISHER FM, CHUI PC, ANTONELLIS PJ, BINA HA, KHARITONENKOV A, FLIER JS, MARATOS-FLIER E: Obesity is a fibroblast growth factor (FGF 21)-resistant state. Diabetes 59: 2781-2789, 2010. 
FRYSTYK L, BERNE C, BERGLUND L, JENSEVIK K, FLYVBJERG A, ZETHELIUS B: Serum adiponectin is a predictor of coronary heart disease: a population-based 10-year follow-up study in elderly men. $J$ Clin Endocrinol Metab 92: 571-576, 2007.

FUNAHASHI T, NAKAMURA T, SHIMOMURA I, MAEDA K, KURIYAMA H, TAKAHASHI M, ARITA Y, KIHARA S, MATSUZAWA Y: Role of adipocytokines on the pathogenesis of atherosclerosis in visceral obesity. Intern Med 38: 202-206, 1999.

FURUNAHASHI M, HOTAMISLIGIL GS: Fatty acid-binding proteins: role in metabolic diseases and potential as a drug targets. Nat Rev Drug Discover 7: 489-503, 2008.

HALUZIK M, PARIZKOVÁ J, HALUZIK MM: Adiponectin and its role in the obesity-induced insulin resistance and related complications. Physiol Res 53: 123-129, 2004.

HALUZIK MM, ANDERLOVA K, DOLEZALOVA R, ADAMIKOVA A, HALUZIKOVA D, HOUSOVA J, SVACINA S, HALUZIK M: Serum adipocyte fatty acid binding protein levels in patients with type 2 diabetes mellitus and obesity: the influence of fenofibrate treatment. Physiol Res 58: 93-99, 2009.

HAN TS, WILLIAMS K, SATTAR N, HUNT KJ, LEAN ME, HAFFNER SM: Analysis of obesity and hyperinsulinemia in the development of metabolic syndrome: San Antonio Heart Study. Obes Res 10: 923-931, 2002.

HOO RC, YEUNG CY, LAM KS, XU A: Inflammatory biomarkers associated with obesity and insulin resistance: a focus on lipocalin-2 and adipocyte fatty acid-binding protein. Expert Rev Endocrinol Metab 3: 29-41, 2008.

HORAKOVA D, PASTUCHA D, STEJSKAL D, KOLLAROVA H, AZEEM K, JANOUT V: Adipocyte fatty acid binding protein and C-reactive protein levels as indicators of insulin resistance development. Biomed Pap Med Fac Univ Palacky Olomouc Czech Rep 155: 355-359, 2011.

HUATING L, JING Z, WEIPING J: Fibroblast growth factor 21: a novel metabolic regulator from pharmacology to physiology. Front Med 7: 25-30, 2013.

IGLESIAS P, SELGAS R, ROMERO S, DÍEZ J: Biological role, clinical significance, and therapeutic possibilities of the recently discovered metabolic hormone fibroblastic growth factor 21. Eur J Endocrinol 167: 301-309, 2012.

KARASEK D, VAVERKOVA H, FRYSAK Z, ORSAG J, NOVOTNY D, HALENKA M, SLAVIK L: Realtionship between serum adipocyte acid-binding protein and endothelial/hemostatic markers in dyslipidemic subjects. Neuroendocrinol Lett 33: 26-31, 2012.

KHARITONENKOV A, WROBLEWSKI V, KOESTER A, CHEN YF, CLUTINGER CK, TIGNO XT, HANSEN BC, SHANAFELT AB, ETGEN GJ: The metabolic state of diabetic monkeys is regulated by fibroblast growth factor 21. Endocrinology 148: 774-781, 2007.

KHARITONENKOV A, DUBNAR JD, BINA HA, BRIGHT S, MOYERS JS, ZHANG C, DING L, MICANOVIC R, MEHRBOD SF, KNIERMAN MD, HALE JE, COSKUN T, SHANAFELT AB: FGF-21/FGF-21 receptor interaction and activation is determined by betaKlotho. J Cell Physiol 215: 1-7, 2008.

KRALISCH S, FASSHAUER M: Fibroblast growth factor 21: effects on carbohydrate and lipid metabolism in health and disease. Curr Opin Clin Nutr Metab Care 14: 354-359, 2011.

KRALISCH S, FASSHAUER M: Adipocyte fatty acid binding protein: a novel adipokine involved in the pathogenesis of metabolic and vascular disease? Diabetologia 56: 10-21, 2013.

LAMOUNIER-ZEPTER V, LOOK C, ALVAREZ J, CHRIST T, RAVENS U, SCHNUCK WH, EHRHARTBORNSTEIN M, BORNSTEIN SR, MORANO I: Adipocyte fatty acid-binding protein suppresses cardiomyocyte contraction: a new link between obesity and heart disease. Circ Res 105: 326-334, 2009.

LIBBY P, OKAMOTO Y, ROCHA VZ, FOLCO E: Inflammation in atherosclerosis: transition from theory to practice. Circ J 74: 213-220, 2011.

LIN Z, WU Z, YIN X, LIU Y, YAN X, LIN S, XIAO J, WANG X, FENG W, LI X: Serum levels of FGF-21 are increased in coronary heart disease patients and are independently associated with adverse lipid profile. $P l o S$ One 5: e15534, 2010.

LINDSAY RS, RESNICK HE, ZHU J, TUN ML, HOWARD BV, ZHANG Y, YEH J, BEST LG: Adiponectin and coronary heart disease: the Strong Heart Study. Arterioscler Thromb Vasc Biol 25: e15-e16, 2005. 
MIYOSHI T, ONOUE G, HIROHATA A, HIROHATA S, USUI S, HINA K, KAWAMURA H, DOI M, KUSANO KF, KUSACHI S, NINOMIYA Y: Serum adipocyte fatty acid-binding protein is independently associated with coronary atherosclerotic burden measured by intravascular ultrasound. Atherosclerosis 211: 164-169, 2010.

PARK SE, RHEE EJ, LEE WY, KIM WJ, YOO SH, BAE JC, CHOI ES, PARK CY, OH KW, PARK SW, KIM SW: The role of serum adipocyte fatty acid-binding protein on the development of metabolic syndrome is independent of pro-inflammatory cytokines. Nutr Metab Cardiovascular Dis 22: 525-532, 2012.

PISCHON T, GIRMAN CJ, HOTAMISLIGIL CS, RIFAI N, HU FB, RIMM EB: Plasma adiponectin levels and risk of myocardial infarction in men. JAMA 291: 1730-1737, 2004.

REINEHR T, WOELFLE J, WUNSCH R, ROTH CL: Fibroblast growth factor 21 (FGF-21) and its relation to obesity, metabolic syndrome, and nonalcoholic fatty liver in children: a longitudinal analysis. J Clin Endocrinol Metab 97: 2143-2150, 2012.

RHEE EJ, LEE WY, PARK CY, OH KW, KIM BJ, SUNG KC, KIM BS: The association of serum adipocyte fatty acid-binding protein with coronary artery disease in Korean adults. Eur J Endocrinol 160: 165-172, 2009.

RYO M, NAKAMURA T, KIHARA S, KUMADA M, SHIBAZAKI S, TAKAHASHI M, NAGAI M, MATSUZAWA Y, FUNAHASHI T: Adiponectin as a biomarker of the metabolic syndrome. Circ J 68: 975-981, 2004.

SAELY CH H, RISCH L, HOEFLE G, REIN P, MUENDLEIN A, MARTE T, ACZEL S, LANGER P, DREXEL H: Low serum adiponectin is independently associated with both the metabolic syndrome and angiographically determined coronary atherosclerosis. Clin Chim Acta 383: 97-102, 2007.

SHIMADA K, MIYAZAKI T, HIROYUKI D: Adiponectin and atherosclerotic disease. Clin Chim Acta 344: 1-12, 2004.

TAO L, GAO E, JIAO X, YUAN Y, LI S, CHRISTOPHER TA, LOPEZ BL, KOCH W, CHAN L, GOLDSTEIN BJ, MA XL: Adiponectin cardioprotection after myocardial ischemia/reperfusion involves the reduction of oxidative/nitrosative stress. Circulation 115: 1408-1416, 2007.

VAVERKOVA H, KARASEK D, NOVOTNY D, KOVAROVA D, HALENKA M, SLAVIK L, FROLICH J: Positive association of adiponectin with soluble thrombomodulin, von Willebrand factor and soluble VCAM-1 in dyslipidemic subjects. Clin Biochem 46: 766-771, 2013.

VON EYNATTEN M, HAMANN A, TWARDELLA D, NAWROTH PP, BRENNER H, ROTHENBACHER D: Relationship of adiponectin with markers of systemic inflammation, atherogenic dyslipidemia, and heart failure in patients with coronary heart disease. Clin Chem 52: 853-859, 2006.

WOO YC, XU A, WANG Y, LAM KS: Fibroblast growth factor 21 as an emerging metabolic regulator. Clin Endocrinol 78: 489-496, 2013.

XU A, VANHOUTTE PM: Adiponectin and adipocyte fatty acid binding protein in the pathogenesis of cardiovascular disease. Am J Physiol Heart Circ Physiol 302: H1231-H1243, 2012.

XU A, WANG Y, XU JY, STEJSKAL D, TAM S, ZHANG J, WAT NM, WONG WK, LAM KS: Adipocyte fatty acid binding protein is a plasma biomarker closely associated with obesity and metabolic syndrome. Clin Chem $\mathbf{5 2}$ : 405-413, 2006.

ZHANG X, YEUNG DC, KARPISEK M, STEJSKAL D, ZHOU ZG, LIU F, WONG RL, CHOW WS, TSO AW, LAM KS, XU A: Serum FGF21 levels are increased in obesity and are independently associated with metabolic syndrome in humans. Diabetes 57: 1246-1253, 2008.

ZHOU M, BAO Y, LU J, ZHOU J, JIA W: Serum A-FABP is increased and closely associated with elevated NTproBNP levels in type 2 diabetic patients treated with rosiglitazone. PLoS One 6: e27032, 2011. 